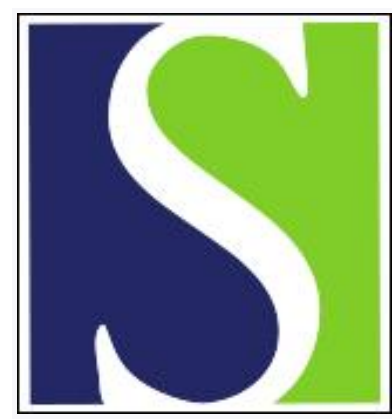

Scand J Work Environ Health 2006;32(3):190-197

https://doi.org/10.5271/sjweh.998

Issue date: 30 Jun 2006

Is an imbalance between physical capacity and exposure to work-related physical factors associated with low-back, neck or shoulder pain?

by Hamberg-van Reenen HH, Ariëns GAM, Blatter BM, van der Beek A], Twisk JWR, van Mechelen W, Bongers PM

Affiliation: Body@work, Research Center Physical Activity, Work and Health, TNO Vumc, Van der Boechorststraat 7, 1081 BT Amsterdam, Netherlands. H.Hamberg@vumc.nl

Refers to the following text of the Journal: 2000;26(1):7-19

The following article refers to this text: 2014;40(6):597-609

Key terms: exposure; imbalance; load-tolerance; low-back pain; musculoskeletal symptom; neck pain; physical capacity; protective effect; risk; shoulder pain; work-related physical factor

This article in PubMed: www.ncbi.nlm.nih.gov/pubmed/16804621 


\title{
Is an imbalance between physical capacity and exposure to work-related physical factors associated with low-back, neck or shoulder pain?
}

\author{
by Heleen H Hamberg-van Reenen, MSc, , , , 3 Geertje AM Ariëns, PhD, , 2 Birgitte M Blatter, PhD,, 3 \\ Allard J van der Beek, PhD, ${ }^{1,2}$ Jos WR Twisk, PhD, ${ }^{4}$ Willem van Mechelen, PhD, MD, ${ }^{1,2}$ \\ Paulien M Bongers, PhD 1, 2,3
}

\begin{abstract}
Hamberg-van Reenen HH, Ariëns GAM, Blatter BM, van der Beek AJ, Twisk JWR, van Mechelen W, Bongers PM. Is an imbalance between physical capacity and exposure to work-related physical factors associated with lowback, neck or shoulder pain? Scand J Work Environ Health 2006;32(3):190-197.
\end{abstract}

\begin{abstract}
Objectives This study investigates whether an imbalance between physical capacity and exposure to workrelated physical factors is associated with low-back, neck, or shoulder pain.

Methods Data of the longitudinal study on musculoskeletal disorders, absenteeism, stress, and health (SMASH), with a follow-up of 3 years $(\mathrm{N}=1789)$, were used. At baseline, physical capacity (isokinetic lifting strength, static muscle endurance, and mobility of the spine) and exposure to work-related physical factors were assessed. During the follow-up, low-back, neck, and shoulder pain were self-reported annually. "Imbalance" was defined as lower than median capacity combined with higher than median exposure, "high balance" was high capacity and high exposure, and "low balance" was low capacity and low exposure.

Results For both the low-back and neck, imbalance between static endurance and working with flexed postures was a risk factor for pain [relative risk (RR) 1.35, 95\% confidence interval (95\% CI) 1.08-1.68, and RR 1.36, 95\% CI 0.96-1.91, respectively]. Low balance was also associated with low-back pain (RR 1.29, 95\% CI 1.041.68). Furthermore, low balance between isokinetic lifting strength and lifting exposure was a risk factor for low-back and neck pain [RR between 1.22 (95\% CI 0.99-1.49) and 1.35 (95\% CI 1.03-1.79)]. No associations were found with shoulder pain.

Conclusions Some relationship between low-back and neck pain and combined measures of physical capacity with exposure to work-related physical factors seems to exist, but an imbalance between physical capacity and exposure was not found to yield higher risks than high balance or low balance.
\end{abstract}

Key terms load-tolerance; musculoskeletal symptom; protective; risk.

Musculoskeletal symptoms are common in the working population and may be caused by high exposure to work-related physical factors (1-5). Next to high exposure, the low capacity of mechanical and physiological responses of the body to an exposure may contribute to the development of musculoskeletal symptoms. Muscle strength, muscle endurance, and joint mobility are examples of proxy measures of physical capacity, which can be measured by different physical tests. The relationship between physical capacity and the risk of musculoskeletal symptoms has been investigated in several longitudinal studies with contradictory results (6-19). However, it may play a role in the risk of musculoskeletal symptoms in combination with high exposure. The biomechanical load-tolerance model defines "load" as physical stresses acting on the body or on anatomical structures within the body and "tolerance" as the capacity of physical and physiological responses of the body to counteract the load (20).

Previously, data of the longitudinal study on musculoskeletal disorders, absenteeism, stress, and health (SMASH) have been used for analyses on the association

1 Body@work, Research Center Physical Activity, Work and Health, TNO VU University Medical Center, Amsterdam, Netherlands.

2 Department of Public and Occupational Health, Institute for Research in Extramural Medicine, VU University Medical Center, Amsterdam, Netherlands.

3 TNO Quality of Life, Hoofddorp, Netherlands.

4 Department of Clinical Epidemiology and Biostatistics, VU University Medical Center, Amsterdam, Netherlands.

Reprint requests to: Willem van Mechelen, Body@work, Research Center Physical Activity, Work and Health, TNO Vumc, Van der Boechorststraat 7, 1081 BT Amsterdam, Netherlands. [E-mail: w.vanmechelen@vumc.nl] 
between exposure to work-related physical factors and low-back or neck pain $(21,22)$ and on the association between physical capacity and low-back, neck, or shoulder pain (12). In these studies, some physical work-related measures, as well as some physical capacity measures, were found to be risk factors. In a study of Harbin et al (23), the incidence of low-back injury was much higher among workers who did not have the lifting strength to perform their job than among workers who had the needed physical capabilities.

We hypothesized that an imbalance between physical capacity and exposure to work-related physical factors is an even more important risk factor with respect to musculoskeletal symptoms than each of these factors on its own. For either high capacity combined with high exposure or low capacity combined with low exposure, we hypothesized only a small increased risk when compared with that of high capacity and low exposure. The main objective of the current study was to determine whether an imbalance between physical capacity (isokinetic muscle strength, static muscle endurance, and mobility of the spine) and exposure to work-related physical factors is associated with low-back, neck, or shoulder pain.

\section{Study population and methods}

\section{Design}

Data from the longitudinal study on musculoskeletal disorders, absenteeism, stress, and health (SMASH) (21, 22), a large prospective cohort study among a working population, were used. Data from about 1800 blue-collar and white-collar workers were collected between March 1994 and March 1997. At baseline, a questionnaire on individual factors, musculoskeletal symptoms, and physical and psychosocial load at work and during leisure time had to be filled out (24-28). Physical load at the workplace was observed using video-recordings. Physical capacity was measured using different tests of isokinetic lifting strength, static endurance of the back, neck and shoulder muscles, and mobility of the lumbar spine. Follow-up questionnaires were sent out three times annually.

\section{Study population}

Of the workers who were invited to participate in SMASH, 1789 (87\%) filled out the baseline questionnaire. For the analyses of this study, employees were excluded if they had worked less than 1 year in their current job $(\mathrm{N}=40)$, worked less than 20 hours per week $(\mathrm{N}=37)$, were receiving sickness benefits or a permanent disability pension $(\mathrm{N}=36)$, or had a second job $(\mathrm{N}=98)$. Furthermore, employees without longitudinal data on low-back, neck, or shoulder pain were excluded $(\mathrm{N}=107, \mathrm{~N}=105$, and $\mathrm{N}=108$, respectively). Finally, employees with missing data on the physical capacity measures in combination with the physical work-related measures were excluded ( $\mathrm{N}=38, \mathrm{~N}=12$, and $\mathrm{N}=13$ for low-back, neck, and shoulder pain, respectively). The result was a dataset of 1291, 1233, and 1227 for the analyses of workers on low-back, neck, and shoulder pain, respectively.

Almost $70 \%$ of the workers was male; the mean age was 35 years. The employees worked 38 hours a week on the average and worked 9 years on the average in their current job. Almost 70\% of the workers had a bluecollar or caring profession, and around 30\% had a whitecollar job.

\section{Low-back, neck and shoulder pain}

Low-back, neck, and shoulder pain were self-reported, using an adapted Dutch version of the Nordic Questionnaire (24). In the baseline and the three follow-up questionnaires, which were sent out once every year, workers were asked if they had low-back, neck, or shoulder pain in the past 12 months. We defined the occurrence of low-back, neck, or shoulder pain if a pain-free episode ("no" or "sometimes" pain) was followed by an episode with pain ("regular" or "prolonged" pain).

\section{Assessment of exposure to work-related physical factors}

Exposure to work-related physical factors at baseline was assessed using video-recordings, as well as self-reports. For about half of the workers, four video-recordings of 10 or 14 minutes were taken randomly during a day. The workers were subdivided into groups with similar tasks. In each of these groups, about half of the videotapes was observed by trained research assistants. These videotapes were analyzed for posture, movement, and force exertion. The exposure to work-related physical factors in the analyzed group was assigned to all of the workers with similar tasks.

\section{Assessment of physical capacity}

Physical capacity was measured at baseline. Before the tests of physical capacity, the employees were asked for contraindications that might involve a health risk or that might affect the results of the tests. Localized musculoskeletal discomfort (LMD) was assessed for a rating of the perceived feelings of discomfort (pain, fatigue, tremor, etc) in any part of the body, ranging from no discomfort (zero) to worst imaginable discomfort (ten) (29). The workers who reported an LMD score of four points or higher in the matching body region were excluded from the tests. In addition, those who reported 
Table 1. Characteristics of the study population in 1994-1997. ( $\mathrm{M}=$ median, $\mathrm{R}=$ range)

\begin{tabular}{|c|c|c|c|c|c|c|c|c|c|c|c|c|c|c|c|}
\hline & \multicolumn{3}{|c|}{$\begin{array}{l}\text { Occurrence of musculoskeletal } \\
\text { symptoms during follow-up }{ }^{a}\end{array}$} & \multicolumn{12}{|c|}{ Baseline exposure to work-related } \\
\hline & \multirow[t]{2}{*}{$\begin{array}{c}\text { Follow-up } \\
1 \\
(\%)\end{array}$} & \multirow[t]{2}{*}{$\begin{array}{c}\text { Follow-up } \\
2 \\
(\%)\end{array}$} & \multirow[t]{2}{*}{$\begin{array}{c}\text { Follow-up } \\
3 \\
(\%)\end{array}$} & \multicolumn{2}{|c|}{$\begin{array}{l}\geq 25-\mathrm{kg} \text { lifts } \\
\text { during an } \\
\text { 8-hour } \\
\text { workday } \\
\text { (N) }\end{array}$} & \multicolumn{2}{|c|}{$\begin{array}{l}\geq 10-\mathrm{kg} \text { lifts } \\
\text { during an } \\
\text { 8-hour } \\
\text { workday } \\
\text { (N) }\end{array}$} & \multicolumn{2}{|c|}{$\begin{array}{l}\text { Worktime } \\
\text { with the } \\
\text { trunk in } \geq 30 \text { - } \\
\text { degree flexion } \\
(\%)\end{array}$} & \multicolumn{2}{|c|}{$\begin{array}{c}\text { Worktime } \\
\text { with the } \\
\text { trunk in } \geq 90 \text { - } \\
\text { degree flexion } \\
(\%)\end{array}$} & \multicolumn{2}{|c|}{$\begin{array}{c}\text { Worktime } \\
\text { with the } \\
\text { trunk in } \geq 30 \text { - } \\
\text { degree rotation } \\
(\%)\end{array}$} & \multicolumn{2}{|c|}{$\begin{array}{l}\text { Worktime } \\
\text { with the } \\
\text { neck in } \geq 20- \\
\text { degree flex- } \\
\text { ion }(\%)\end{array}$} \\
\hline & & & & M & $\mathrm{R}$ & M & $\mathrm{R}$ & M & $\mathrm{R}$ & M & $\mathrm{R}$ & M & $\mathrm{R}$ & M & $\mathrm{R}$ \\
\hline $\begin{array}{l}\text { Low-back pain } \\
(\mathrm{N}=1291)\end{array}$ & 8.9 & 10.7 & 6.8 & 0 & $0-172$ & 8 & $0-1401$ & 5 & $0-60$ & 0 & $0-15$ & 3 & $0-32$ & $\cdot$ & .. \\
\hline $\begin{array}{l}\text { Neck pain } \\
(\mathrm{N}=1233)\end{array}$ & 5.8 & 6.8 & 3.7 & $\cdot$ &.$\cdot$ & 8 & $0-1401$ & $\cdot$ & .. & $\cdot$ &.$\cdot$ & $\cdot$ & $\cdot$. & 35 & $0-79$ \\
\hline $\begin{array}{l}\text { Shoulder pain } \\
(\mathrm{N}=1227)\end{array}$ & 6.8 & 3.7 & 5.7 & $\cdot$ &.$\cdot$ & 8 & $0-1401$ & $\cdot$ &.$\cdot$ & $\cdot$ &.$\cdot$ & $\cdot$ & $\cdot \cdot$ & $\cdot$ &.$\cdot$ \\
\hline
\end{tabular}

a A pain-free episode ("no" or "sometimes" pain in the past 12 months) was followed by an episode with pain ("regular" or "prolonged" pain in the past 12 months).

cardiovascular diseases, fever, or pregnancy were excluded.

Isokinetic lifting strength of the back muscles and the neck-shoulder muscles was measured using an Aristokin dynamometer (Lode BV Medical Technology, Groningen, Netherlands). The workers were asked to lift a box isokinetically from the floor to hip level for the trunk muscles and from the hip to shoulder level for the neck-shoulder muscles. Static endurance of the back extensors was measured using the Biering-Sørensen test (9). The test was terminated when the workers reached an LMD score of five for the back region, a score of seven for another part of the body, or when 4 minutes were completed. Static endurance of the neck extensors was measured using a helmet of 5 kilograms for the men and 2.5 kilograms for the women. The workers had to keep their head flexed at 45 degrees in a sitting posture. For the measurement of the static endurance of the shoulder elevators, the workers had to keep their arms elevated at 90 degrees in a sitting posture, while carrying a load of 2.5 kilograms for the men and 1.5 kilograms for the women. The tests for the neck and shoulders were terminated at an LMD score of five for the neck-shoulder region or a score of seven for another part of the body or after 7 minutes. Lumbar flexion was measured by the Schöber test (30). Rotation of the spine was measured by the difference in the distance between the incisura jugularis and the L5 disc in a posture of maximum rotation and in the neutral posture (12).

\section{Imbalance between physical capacity and exposure to work-related physical factors}

The work-related physical capacity measures and exposure variables were combined to define the balance and imbalance groups. Isokinetic lifting strength was combined with the number of lifts during an 8-hour workday. Furthermore, either static endurance or mobility of the spine was combined with the worktime in a specific posture. Due to the absence of a biological cut-off point, "imbalance" was defined as lower than the median score of physical capacity and higher than the median score of physical exposure. "High balance" was defined as both high capacity and high exposure, and "low balance" was defined as both low capacity and low exposure. The workers with high capacity and low exposure were considered to be the reference group.

\section{Data analyses}

We estimated univariate and multivariate relative risks (RR) and $95 \%$ confidence intervals $(95 \% \mathrm{CI})$ for both balance groups and the imbalance group with respect to the reference group. Data were analyzed using Poisson generalized estimation equations (GEE) (Stata version 7.0, Stata Corporation, College Station, TX, USA).

In the multivariate analyses, gender and age were selected as confounders related to low-back, neck or shoulder pain a priori. Furthermore, the follow-up time was selected beforehand to adjust for the fact that the association between imbalance at baseline and musculoskeletal symptoms during the follow-up could be stronger after 1 year than after 2 or 3 years. All other potential confounding factors were analyzed separately. Potential confounders were measured at baseline, including body height, body mass index, years of employment, number of workhours per week, education, previous low-back, neck or shoulder pain, co-morbidity regarding other musculoskeletal symptoms at baseline and during follow-up, self-reported general health status, self-reported physical fitness, exposure to workrelated psychosocial risk factors (27), physical load during leisure time $(25,31)$, coping style $(28)$, and exposure to life events.

All of the potential confounding factors were added as time-independent variables to the models, except for co-morbidity regarding other musculoskeletal symptoms, which was added as a time-dependent variable. If 


\begin{tabular}{|c|c|c|c|c|c|c|c|c|c|c|c|c|c|c|c|c|c|c|c|}
\hline \multicolumn{6}{|c|}{ physical factors } & \multicolumn{14}{|c|}{ Baseline physical capacity } \\
\hline \multirow{2}{*}{\multicolumn{2}{|c|}{$\begin{array}{l}\text { Worktime with } \\
\geq 30 \text {-degree } \\
\text { upper-arm } \\
\text { elevation } \\
(\%)\end{array}$}} & \multirow{2}{*}{\multicolumn{2}{|c|}{$\begin{array}{l}\text { Worktime with } \\
\geq 90 \text {-degree } \\
\text { upper-arm } \\
\text { elevation } \\
(\%)\end{array}$}} & \multirow{2}{*}{\multicolumn{2}{|c|}{$\begin{array}{l}\text { Worktime } \\
\text { carrying out } \\
\text { repeated } \\
\text { movements } \\
(\%)\end{array}$}} & \multicolumn{4}{|c|}{ Isokinetic lifting-strength } & \multirow{2}{*}{\multicolumn{2}{|c|}{$\begin{array}{l}\text { Static endu- } \\
\text { rance of } \\
\text { the back } \\
\text { muscels } \\
\text { (seconds) }\end{array}$}} & \multirow{2}{*}{\multicolumn{4}{|c|}{$\begin{array}{l}\text { Static endu- Static endu- } \\
\text { rance of the rance of the } \\
\text { neck muscles } \\
\text { (seconds) } \\
\begin{array}{cc}\text { (secolder } \\
\text { (seconds) }\end{array}\end{array}$}} & \multirow{2}{*}{\multicolumn{2}{|c|}{$\begin{array}{l}\text { Flexion of } \\
\text { the spine } \\
(\mathrm{cm})\end{array}$}} & \multirow{2}{*}{\multicolumn{2}{|c|}{$\begin{array}{l}\text { Rotation } \\
\text { of the } \\
\text { spine } \\
\text { (cm) }\end{array}$}} \\
\hline & & & & & & \multicolumn{2}{|c|}{$\begin{array}{l}\text { Back muscles } \\
\text { (N) }\end{array}$} & \multicolumn{2}{|c|}{$\begin{array}{l}\text { Neck-shoulder } \\
\text { muscles (N) }\end{array}$} & & & & & & & & & & \\
\hline M & $\mathrm{R}$ & M & $\mathrm{R}$ & M & $\mathrm{R}$ & M & $\mathrm{R}$ & M & $\mathrm{R}$ & M & $\mathrm{R}$ & M & $\mathrm{R}$ & $M$ & $\mathrm{R}$ & M & $\mathrm{R}$ & M & $\mathrm{R}$ \\
\hline . & .. & . & .. & . & .. & 474 & $39-1358$ & . &.. & 90 & $5-240$ & . &.. & . & .. & 7.0 & $0.5-10.0$ & 5.5 & $1.4-12.8$ \\
\hline . & .. & . & .. & . & .. & . &.. & 208 & $15-563$ & . & .. & 280 & $7-420$ & . & .. & . & .. & . & .. \\
\hline 36 & $8-87$ & 0 & $0-43$ & 0 & $0-92$ & . & .. & 208 & $15-563$ & . & .. & . & .. 2 & 253 & $27-420$ & . & .. & . & .. \\
\hline
\end{tabular}

the crude beta coefficients changed at least $10 \%$ by adding, the confounder was included in the final multivariate models. However, some of these confounders were excluded because of mutual dependency (Spearman correlation coefficients $\geq 0.5$ or $\leq-0.5$ ). Finally, interaction terms with age and gender were added to the GEE models to investigate the extent to which the relationships were modified by these variables.

\section{Results}

\section{Characteristics of the study population}

The 12-month baseline prevalence rates for regular or prolonged low-back, neck, and shoulder pain among the workers were $31 \%, 22 \%$, and $9 \%$, respectively. The occurrences of an episode of regular or prolonged musculoskeletal pain during the follow-up, after no or sometime pain in the previous year, varied between $7 \%$ and $11 \%$ for low-back pain, between $4 \%$ and $7 \%$ for neck pain, and between $6 \%$ and $7 \%$ for shoulder pain (see table 1).

Table 1 also presents the median and range of physical capacity and the exposure to work-related physical factors for the study population. For the number of lifts of $\geq 25$ kilograms during an 8-hour workday, the worktime with the trunk in $\geq 90$ degree flexion or $\geq 90$ degree upper-arm elevation, and the worktime carrying out repeated movements, the median was zero, which means that fewer than half of the workers were exposed to these work-related factors.

\section{Low-back pain}

Table 2 shows the results of the univariate and multivariate GEE analyses of the association between combined measures of physical capacity and exposure to work-related physical factors and the risk of low-back
Table 2. Univariate and multivariate relative risks (RR) and $95 \%$ confidence intervals $(95 \% \mathrm{Cl})$ of the association between combined measures of physical capacity and exposure to workrelated physical factors and low-back pain in 1994-1997 in the Iongitudinal study on musculoskeletal disorders, absenteeism, stress, and health (SMASH) $(\mathrm{N}=1291)$.

\begin{tabular}{|c|c|c|c|c|}
\hline \multirow{2}{*}{$\begin{array}{l}\text { Combined measures } \\
\text { of physical capacity } \\
\text { and exposure to } \\
\text { work-related } \\
\text { physical factors }\end{array}$} & \multicolumn{4}{|c|}{$\begin{array}{l}\text { Cut-off at median physical capacity and } \\
\text { median physical exposure a }\end{array}$} \\
\hline & $\begin{array}{l}\text { Crude } \\
\operatorname{RR}^{b}\end{array}$ & $\begin{array}{l}95 \% \mathrm{Cl} \\
\text { for the } \\
\text { crude RR }\end{array}$ & $\begin{array}{l}\text { Adjusted } \\
\text { RR }\end{array}$ & $\begin{array}{c}95 \% \mathrm{Cl} \\
\text { for the } \\
\text { adjusted RR }\end{array}$ \\
\hline \multicolumn{5}{|c|}{ Isokinetic lifting strength (N) \& lifting $\geq 25 \mathrm{~kg}$ at work } \\
\hline Reference group & 1.00 & $\cdot$ & $1.00^{c}$ & . \\
\hline High & & $0.94-1$ & & $0.92-1.49$ \\
\hline & & $1.01-1$ & & $.99-1.49$ \\
\hline Imbalance group & & $0.92-1.44$ & & $0.92-1.45$ \\
\hline \multicolumn{5}{|c|}{ Isokinetic lifting strength $(\mathrm{N})$ \& lifting $\geq 10 \mathrm{~kg}$ at work } \\
\hline & & $\cdot$ & & \\
\hline & & $0.85-1.32$ & & $0.83-1.30$ \\
\hline & & $0.97-1$ & & $0.96-1.54$ \\
\hline Imbalance group & & $0.92-1.41$ & & $0.92-1.42$ \\
\hline \multicolumn{5}{|c|}{ Static endurance \& trunk flexion $\geq 30$ degrees at work } \\
\hline & & $\cdot$ & & $\cdot$ \\
\hline & & $0.78-1$ & & $.78-1.24$ \\
\hline & & $1.05-1$ & & $1.04-1.59$ \\
\hline Imbalance group & 1.32 & $1.06-1.64$ & 1.35 & $1.08-1.68$ \\
\hline \multicolumn{5}{|c|}{ Maximum flexion of the spine $\&$ trunk flexion $\geq 90$ degrees at work } \\
\hline Reference group & 1.00 & $\cdot$ & & $\cdot$ \\
\hline & & $0.78-1$ & & $0.77-1.16$ \\
\hline w-balance group & & $0.84-1.22$ & & $0.83-1.21$ \\
\hline Imbalance group & 1.09 & $0.91-1.31$ & 1.09 & $0.91-1.31$ \\
\hline \multicolumn{5}{|c|}{ Maximum rotation of the spine $\&$ trunk rotation $\geq 30$ degrees at work } \\
\hline Reference group & 1.00 & $\cdot$ & $1.00^{d}$ & • \\
\hline & & $0.82-1.22$ & & $0.76-1.26$ \\
\hline Low-balance group & & $0.91-1.35$ & & $0.71-1.23$ \\
\hline Imbalance group & 1.25 & $1.03-1.51$ & 1.19 & $0.93-1.52$ \\
\hline
\end{tabular}

a High balance was defined as higher than median physical capacity combined with higher than median physical exposure; low balance was defined as lower than median physical exposure combined with lower than median physical capacity; imbalance was defined as lower than median physical capacity combined with higher than median physical exposure; and the reference was defined as higher than median physical capacity combined with lower than median physical exposure.

${ }^{b}$ Adjusted for follow-up time.

c Adjusted for follow-up time, gender, and age.

adjusted for follow-up time, gender, age, isokinetic lifting strength, and number of years of sports participation in the past. 
pain. Low balance between isokinetic lifting strength and exposure to lifting at work was borderline significantly associated with low-back pain (RR 1.22). Furthermore, imbalance or low balance between static endurance of the back muscles and flexion at work was associated with low-back pain (RR 1.29 and 1.35, respectively). For the other imbalance or low balance combinations, no associations were found with low-back pain, or for any of the high balance combinations.

\section{Neck pain}

Table 3 shows the results of two combined measures for neck pain. The workers who had low isokinetic lifting strength and did not often have to lift at work had an increased risk of neck pain (RR 1.35). Imbalance between static endurance of the neck muscles and flexion of the neck at work was associated with a borderline significantly increased risk of neck pain (RR 1.36).

\section{Shoulder pain}

The results of the univariate analyses showed increased risks of shoulder pain for most of the combined measures, but, after adjustment for confounders, no association remained (see table 4).

Table 3. Univariate and multivariate relative risks (RR) and $95 \%$ confidence intervals $(95 \% \mathrm{Cl})$ of the association between combined measures of physical capacity and exposure to workrelated physical factors and neck pain in 1994-1997 in the longitudinal study on musculoskeletal disorders, absenteeism, stress, and health (SMASH) $(\mathrm{N}=1233)$.

\begin{tabular}{|c|c|c|c|c|}
\hline \multirow{2}{*}{$\begin{array}{l}\text { Combined measures } \\
\text { of physical capacity } \\
\text { and exposure to } \\
\text { work-related } \\
\text { physical factors }\end{array}$} & \multicolumn{4}{|c|}{$\begin{array}{l}\text { Cut-off at median physical capacity } \\
\text { and median physical exposure }\end{array}$} \\
\hline & $\begin{array}{l}\text { Crude } \\
\operatorname{RR}^{\mathrm{b}}\end{array}$ & $\begin{array}{l}95 \% \mathrm{Cl} \\
\text { for the } \\
\text { crude RR }\end{array}$ & $\begin{array}{l}\text { Adjusted } \\
\text { RR }\end{array}$ & $\begin{array}{c}95 \% \mathrm{Cl} \\
\text { for the } \\
\text { adjusted } \mathrm{RR}\end{array}$ \\
\hline \multicolumn{5}{|c|}{ Isokinetic lifting strength (N) \& lifting $\geq 10 \mathrm{~kg}$ at work } \\
\hline Reference group & 1.00 & . & $1.00^{c}$ & . \\
\hline High-balance group & 0.76 & $0.54-1.08$ & 1.00 & $0.72-1.40$ \\
\hline Low-balance group & 1.99 & $1.51-2.62$ & & $1.03-1$ \\
\hline Imbalance group & 1.31 & $0.96-1.78$ & 1.20 & $0.88-1.62$ \\
\hline \multicolumn{5}{|c|}{ Static endurance \& neck flexion $\geq 20$ degrees at work } \\
\hline Reference group & 1.00 & . & $1.00^{d}$ & . \\
\hline High-balance group & 1.38 & $1.00-1.89$ & 1.11 & $0.78-1.57$ \\
\hline Low-balance group & 1.32 & $0.94-1.85$ & 0.96 & .42 \\
\hline Imbalance group & 2.07 & $1.53-2.79$ & 1.36 & $0.96-1.91$ \\
\hline \multicolumn{5}{|c|}{$\begin{array}{l}\text { a High balance was defined as higher than median physical capacity com- } \\
\text { bined with higher than median physical exposure; low balance was de- } \\
\text { fined as lower than median physical exposure combined with lower than } \\
\text { median physical capacity; imbalance was defined as lower than median } \\
\text { physical capacity combined with higher than median physical exposure; } \\
\text { and the reference was defined as higher than median physical capacity } \\
\text { combined with lower than median physical exposure. } \\
\text { b Adjusted for follow-up time. } \\
\text { c Adjusted for follow-up time, gender, age, length, education, and previ- } \\
\text { ous neck pain. } \\
\text { d Adjusted for follow-up time, gender, age, co-morbidity of low-back or } \\
\text { shoulder pain, previous neck pain, isokinetic lifting strength of the neck- } \\
\text { shoulder muscles, and number of years of sports participation in the } \\
\text { past. }\end{array}$} \\
\hline
\end{tabular}

Table 4. Univariate and multivariate relative risks (RR) and $95 \%$ confidence intervals $(95 \% \mathrm{Cl})$ of the association between combined measures of physical capacity and exposure to workrelated physical factors and shoulder pain in 1994-1997 in the longitudinal study on musculoskeletal disorders, absenteeism, stress, and health (SMASH) $(\mathrm{N}=1227)$.

\begin{tabular}{|c|c|c|c|c|}
\hline \multirow{2}{*}{$\begin{array}{l}\text { Combined measures } \\
\text { of physical capacity } \\
\text { and exposure to } \\
\text { work-related } \\
\text { physical factors }\end{array}$} & \multicolumn{4}{|c|}{$\begin{array}{l}\text { Cut-off at median physical capacity } \\
\text { and median physical exposure a }\end{array}$} \\
\hline & $\begin{array}{l}\text { Crude } \\
\operatorname{RR}^{b}\end{array}$ & $\begin{array}{l}95 \% \mathrm{Cl} \\
\text { for the } \\
\text { crude RR }\end{array}$ & $\begin{array}{l}\text { Adjusted } \\
\text { RR }\end{array}$ & $\begin{array}{c}95 \% \mathrm{Cl} \\
\text { for the } \\
\text { adjusted RR }\end{array}$ \\
\hline
\end{tabular}

Isokinetic lifting strength ( $\mathrm{N})$ \& lifting $\geq 10 \mathrm{~kg}$ at work

$\begin{array}{llclc}\text { Reference group } & 1.00 & . & 1.00^{c} & . \\ \text { High-balance group } & 0.86 & 0.63-1.17 & 0.71 & 0.48-1.06 \\ \text { Low-balance group } & 1.73 & 1.31-2.27 & 1.09 & 0.71-1.65 \\ \text { Imbalance group } & 1.38 & 1.04-1.84 & 0.76 & 0.51-1.13\end{array}$

Isokinetic lifting strength (N) \& upper-arm elevation $\geq 30$ degrees at work

$\begin{array}{llccc}\text { Reference group } & 1.00 & \cdot & 1.00^{\mathrm{d}} & . \\ \text { High-balance group } & 0.93 & 0.68-1.27 & 0.80 & 0.60-1.07 \\ \text { Low-balance group } & 1.53 & 1.16-2.02 & 0.90 & 0.67-1.22 \\ \text { Imbalance group } & 1.75 & 1.34-2.30 & 1.08 & 0.82-1.43\end{array}$

Isokinetic lifting strength (N) \& upper-arm elevation $\geq 90$ degrees at work

$\begin{array}{lllll}\text { Reference group } & 1.00 & . & 1.00 & . \\ \text { High-balance group } & 0.84 & 0.62-1.15 & 0.71 & 0.49-1.02 \\ \text { Low-balance group } & 1.65 & 1.25-2.17 & 1.02 & 0.71-1.46 \\ \text { Imbalance group } & 1.48 & 1.12-1.94 & 0.94 & 0.66-1.34\end{array}$

Static endurance \& upper-arm elevation $\geq 30$ degrees at work

$\begin{array}{lllll}\text { Reference group } & 1.00 & . & 1.00^{4} & . \\ \text { High-balance group } & 1.06 & 0.79-1.40 & 1.00 & 0.78-1.29 \\ \text { Low-balance group } & 1.38 & 1.05-1.80 & 1.08 & 0.85-1.37 \\ \text { Imbalance group } & 1.29 & 0.99-1.69 & 1.06 & 0.84-1.34\end{array}$

Static endurance \& upper-arm elevation $\geq 90$ degrees at work

$\begin{array}{lllll}\text { Reference group } & 1.00 & . & 1.00^{9} & . \\ \text { High-balance group } & 0.86 & 0.51-0.91 & 0.75 & 0.52-1.08 \\ \text { Low-balance group } & 1.14 & 0.88-1.48 & 0.91 & 0.66-1.23 \\ \text { Imbalance group } & 1.08 & 0.84-1.39 & 0.93 & 0.68-1.25\end{array}$

Static endurance \& repeated movements at work

$\begin{array}{lcccc}\text { Reference group } & 1.00 & . & 1.00^{\mathrm{h}} & . \\ \text { High-balance group } & 1.02 & 0.75-1.38 & 0.93 & 0.65-1.32 \\ \text { Low-balance group } & 1.27 & 1.01-1.60 & 0.98 & 0.73-1.33 \\ \text { Imbalance group } & 1.38 & 1.03-1.84 & 0.94 & 0.67-1.31\end{array}$

a High balance was defined as higher than median physical capacity combined with higher than median physical exposure; low balance was defined as lower than median physical exposure combined with lower than median physical capacity; imbalance was defined as lower than median physical capacity combined with higher than median physical exposure; and the reference was defined as higher than median physical capacity combined with lower than median physical exposure.

${ }^{\mathrm{b}}$ Adjusted for follow-up time.

c Adjusted for follow-up time, gender, age, length, workhours per week, working with the arms above shoulder level, number of years of sports participation in the past, and decision authority.

${ }^{d}$ Adjusted for follow-up time, gender, age, and co-morbidity of low-back or neck pain.

${ }^{\text {e }}$ Adjusted for follow-up time, gender, age, length, workhours per week, co-morbidity of low-back or neck pain, and number of years of sports participation in the past.

${ }^{\dagger}$ Adjusted for follow-up time, gender, age, and co-morbidity of low-back or neck pain.

${ }^{g}$ Adjusted for follow-up time, gender, age, co-morbidity of low-back or neck pain, isokinetic lifting strength, and number of years of sports participation in the past.

h Adjusted for follow-up time, gender, age, length, co-morbidity of lowback or neck pain, isokinetic lifting strength, number of years of sports participation in the past, and decision authority. 


\section{Interaction with gender and age}

We included interaction terms with age and gender into the multivariate GEE models to investigate the extent to which the relationships were modified by these variables. Statistically significant interaction effects (P-value $\leq 0.10$ ) with gender were found for some of the variables, but only one interaction effect with age was found.

For low-back pain, interaction effects were found for low balance and imbalance between isokinetic lifting strength and lifting at work, with an increased risk among men [adjusted RR varying between 1.25 (95\% CI 0.97-1.62) and 1.41 (95\% CI 1.04-1.91)], but no effect among women [adjusted RR varying between 0.80 (95\% CI 0.55-1.18) and 0.89 (95\% CI 0.64-1.24)]. Furthermore, an interaction effect was found for high balance or imbalance between static endurance and flexion at work with a borderline significantly increased risk for imbalance among the men (RR 1.22, 95\% CI 0.981.53 ) and no effect among the women (RR 0.84, 95\% CI 0.61-1.16).

For neck pain, an interaction effect was found for high balance between isokinetic lifting strength and lifting at work with a nonstatistically significant effect among the women (RR 4.03, 95\% CI 0.83-19.49), but no effect among the men (RR $0.92,95 \%$ CI $0.66-1.29$ ). For this combined measure, no effect was found for the whole population.

For shoulder pain, an interaction effect was found for low balance between static endurance and repeated movements at work with a nonstatistically significant effect among the women (RR 1.46, 95\% CI 0.60-3.57), but no effect was found among the men (RR $0.67,95 \%$ CI 0.41-1.10). Furthermore, a negative interaction effect was found for age, and, therefore, the effect was weaker for the workers with a higher age. For this combined measure, no effect was found for the whole population.

\section{Discussion}

\section{Main results}

Our study reports on the risk of low-back, neck, or shoulder pain for workers who are in balance or imbalance with regard to physical capacity and exposure to work-related physical factors. For low-back and neck pain, the results of our study partly supported our hypothesis that an imbalance between physical capacity and exposure to work-related physical factors would lead to an increased risk. However, our hypothesis that imbalance would yield a higher risk than low or high balance was not supported, because we found that the risks of musculoskeletal symptoms for the low balance combinations (ie, low capacity in combination with low exposure) were often higher than those for the imbalance combinations. Finally, our results suggested that low balance may be a more important risk factor for musculoskeletal symptoms than high balance (ie, high capacity in combination with high exposure).

More specifically, for both the neck and the lowback, imbalance between static endurance and exposure to flexion was a risk factor for pain, and low balance was a risk factor for low-back pain. Low balance between isokinetic lifting strength and exposure to lifting at work was a risk factor for low-back, and neck pain. For all other balance and imbalance combinations, no associations with musculoskeletal symptoms were found. The analyses stratified for gender yielded inconsistent results.

\section{Comparison with former research}

As far as we know, no previous study combined physical capacity measures with exposure to work-related physical factors as risk factors of future musculoskeletal symptoms among healthy workers. However, in studies with functional capacity evaluations, physical capacity was found to be related to specific job demands $(23,32)$. Harbin \& Olsen (23) found that job lifting requirements in association with lifting ability correlates with work injury incidence (ie, any musculoskeletal work-related incident that resulted in absence).

The results of our study can be compared with the results of previous studies on exposure to work-related physical factors $(21,22)$ and those on physical capacity (12) using SMASH data. However, different statistical analysis techniques, different cut-off points, and different selections of the study population were used. In our present study, we found that, for both the low-back and the neck, imbalance between static endurance and exposure to flexion was a risk factor for pain. This finding was consistent with those of previous studies, in which both working in flexion $(21,22)$ and with low static endurance (12) have been found to be risk factors on their own. Furthermore, our results regarding low balance between isokinetic lifting strength and lifting at work as a risk factor for low-back and neck pain were partly consistent with previous results. Low isokinetic lifting strength was not found to be a risk factor for low-back pain (12). Overall, these findings support our hypothesis that an imbalance between physical capacity and exposure to physical factors may be a more important predictor of low-back or neck pain than the effects of each of these variables on its own.

\section{Methodological considerations}

The strengths of our study were the large study population and the prospective cohort study design with a 
follow-up of 3 years. Furthermore, both physical capacity and exposure to work-related physical factors were assessed in an appropriate way. For exposure to physical factors, we only used data obtained from observations from video-recordings. Physical capacity was measured using physical tests with satisfactory clinimetric characteristics. Self-reports of musculoskeletal symptoms were assessed three times during the followup.

However, some limitations can be mentioned with regard to this study. First, we decided to use median physical capacity and median physical exposure as cutoff points to define imbalance because biological cutoff points were not available, except for the Schöber test (33). This was an arbitrary choice. To investigate the effect of the cut-off points, we performed additional analyses for more extreme groups. Imbalance was defined as the lowest $30 \%$ of capacity combined with the highest $30 \%$ of exposure, high balance as the highest $30 \%$ of capacity and the highest $30 \%$ of exposure, and low balance as the lowest $30 \%$ of capacity and the lowest $30 \%$ of exposure. For neck pain, this division generally led to a slight increase in the strength of effects, especially for the imbalance and low balance groups. However, for low-back and shoulder pain, no differences were found.

Second, we assumed that the association between imbalance at baseline and the risk of low-back, neck, or shoulder pain would be stronger after 1 year than after 2 or 3 years of follow-up. Therefore, follow-up time was included in the analyses as a potential confounder. In addition, to examine whether our assumption was correct, we carried out univariate analyses and included the interaction term with follow-up time. A statistically significant negative interaction effect was found only for two combined measures. Therefore, it could be concluded that the relation between imbalance and the risk of musculoskeletal symptoms did not change substantially during the follow-up of 3 years.

Third, the effects could have been influenced by measurement errors of the physical tests.

Test-retest reliability and inter-rater reliability were investigated in four pilot studies among healthy people (15 students and 18 workers). Two physiotherapists carried out the tests of physical capacity twice with an interval of 1 week between the two. The average results of these pilot studies showed high test-retest reliability (Pearson correlation coefficient of more than 0.75 and P-value of the paired t-test of more than 0.40) but moderate inter-rater reliability (Pearson correlation coefficient between 0.50 and 0.75 and P-value of the paired $\mathrm{t}$-test between 0.10 and 0.40 ) for the isokinetic neckshoulder lifting test and the back endurance test. The test-retest reliability and inter-rater reliability were moderate for the other tests of physical capacity. Therefore, nondifferential misclassification could not completely be excluded from our study in that it might have led to an underestimation of the real effect.

Finally, it should be kept in mind that, within workers, the degree of imbalance or balance between physical capacity and physical exposure can be considered to be dynamic (34) (ie, high physical exposure could lead to an increase in physical capacity) due to a training effect. It is plausible that there will be an optimum in this relationship, because prolonged exposure to physical factors could lead to tissue damage, which could result in decreased physical capacity (35).

\section{Concluding remarks}

In general, the results of this study suggest that imbalance between static endurance of the back or neck muscles and exposure to flexed postures of these body parts is a risk factor for low-back and neck pain, respectively. Furthermore, low balance between isokinetic lifting strength and lifting at work was found to be a risk factor for low-back and neck pain. No other balance or imbalance combinations were found to be risk factors of musculoskeletal symptoms.

For several combined measures, imbalance and low balance were found to be a risk factor for musculoskeletal symptoms, but high balance was not found to be a risk factor. The results need to be confirmed by other studies focusing on the imbalance between physical capacity and exposure.

\section{References}

1. Ariëns GAM, van Mechelen W, Bongers PM, Bouter LM, van der Wal G, Jansson E. Physical risk factors for neck pain [review]. Scand J Work Environ Health. 2000;26(1):7-19.

2. Hoogendoorn WE, van Poppel MNM, Bongers PM, Koes BW, Bouter LM. Physical load during work and leisure time as risk factors for back pain [review]. Scand J Work Environ Health. 1999;25(5):387-403.

3. Lötters F, Burdorf A, Kuiper J, Miedema H. Model for the work-relatedness of low-back pain [review]. Scand J Work Environ Health. 2003;29(6):431-40.

4. Malchaire J, Cock N, Vergracht S. Review of the factors associated with musculoskeletal problems in epidemiological studies. Int Arch Occup Environ Health. 2001;74(2):79-90.

5. Van der Windt DA, Thomas E, Pope DP, de Winter AF, Macfarlane GJ, Bouter LM, et al. Occupational risk factors for shoulder pain: a systematic review. Occup Environ Med. 2000;57(7):433-42.

6. Barnekow-Bergkvist M, Hedberg GE, Janlert U, Jansson E. Determinants of self-reported neck-shoulder and low back symptoms in a general population. Spine. 1998;23(2):235-43.

7. Battié MC, Bigos SJ, Fisher LD, Hansson TH, Jones ME, Wortley MD. Isometric lifting strength as a predictor of industrial back pain reports. Spine. 1989;14(8):851-6. 
8. Battié MC, Bigos SJ, Fisher LD, Spengler DM, Hansson TH, Nachemson AL, et al. The role of spinal flexibility in back pain complaints within industry: a prospective study. Spine. 1990;15(8):768-73.

9. Biering-Sørensen F. Physical measurements as risk indicators for low-back trouble over a one-year period. Spine. 1984;9(2):106-19.

10. Biering-Sørensen F, Thomsen CE, Hilden J. Risk indicators for low back trouble. Scand J Rehabil Med. 1989;21(3):1517.

11. Gibbons LE, Videman T, Battié MC. Isokinetic and psychophysical lifting strength, static back muscle endurance, and magnetic resonance imaging of the paraspinal muscles as predictors of low back pain in men. Scand J Rehabil Med. 1997;29(3):187-91.

12. Hamberg-van Reenen HH, Ariëns GAM, Blatter BM, Twisk JWR, van Mechelen W, Bongers PM. Physical capacity in relation to low back, neck, or shoulder pain in a working population. Occup Environ Med. 2006;63(6)371-7.

13. Kujala UM, Taimela S, Viljanen T, Jutila H, Viitasalo JT, Videman T, et al. Physical loading and performance as predictors of back pain in healthy adults. A 5-year prospective study. Eur J Appl Physiol Occup Physiol. 1996;73(5):452-8.

14. Leino P, Aro S, Hasan J. Trunk muscle function and low back disorders: a ten-year follow-up study. J Chronic Dis. 1987;40(4):289-96.

15. Luoto S, Heliövaara M, Hurri H, Alaranta H. Static back endurance and the risk of low-back pain. Clin Biomech. 1995;10(6):323-4.

16. Masset DF, Piette AG, Malchaire JB. Relation between functional characteristics of the trunk and the occurrence of low back pain: associated risk factors. Spine. 1998;23(3):359-65.

17. Riihimäki H, Wickström G, Hänninen K, Luopajärvi T. Predictors of sciatic pain among concrete reinforcement workers and house painters-a five-year follow-up. Scand J Work Environ Health. 1989;15(6):415-23.

18. Stevenson JM, Weber CL, Smith JT, Dumas GA, Albert WJ. A longitudinal study of the development of low back pain in an industrial population. Spine. 2001;26(12):1370-7.

19. Takala EP, Viikari-Juntura E. Do functional tests predict low back pain?. Spine. 2000;25(16):2126-32.

20. Panel on Musculoskeletal Disorders and the Workplace, Commission on Behavioral and Social Sciences and Education, National Research Council and Institute of Medicine. Musculoskeletal disorders and the workplace: low back and upper extremities. Washington (DC): National Academy Press; 2001.

21. Ariëns GAM, Bongers PM, Douwes M, Miedema MC, Hoogendoorn WE, van der Wal G, et al. Are neck flexion, neck rotation, and sitting at work risk factors for neck pain? Results of a prospective cohort study. Occup Environ Med. 2001; 58(3):200-7.
22. Hoogendoorn WE, Bongers PM, de Vet HCW, Douwes M, Koes BW, Miedema MC, et al. Flexion and rotation of the trunk and lifting at work are risk factors for low back pain: results of a prospective cohort study. Spine. 2000; 25(23):3087-92.

23. Harbin G, Olson J. Post-offer, pre-placement testing in industry. Am J Ind Med. 2005;47(4):296-307.

24. Kuorinka I, Jonsson B, Kilbom Å, Vinterberg H, BieringSørensen F, Andersson G, et al. Standardized Nordic questionnaires for the analysis of musculoskeletal symptoms. Appl Ergon. 1987;18(3):233-7.

25. Hildebrandt VH, Douwes M. Lichamelijke belasting en arbeid: vragenlijst bewegingsapparaat (Physical load and work: questionnaire on musculoskeletal load and health complaints). Voorburg (The Netherlands): Ministerie van Sociale Zaken en Werkgelegenheid, Directoraat-Generaal van de Arbeid; 1991.

26. Hosman CMH. Psychosociale problemen en hulp zoeken (Psychosocial problems and care-seeking). Lisse (Netherlands): Swets\&Zeitlinger; 1983.

27. Karasek R, Brisson C, Kawakami N, Houtman I, Bongers P, Amick B. The Job Content Questionnaire (JCQ): an instrument for internationally comparative assessments of psychosocial job characteristics. J Occup Health Psychol. 1998; 3(4):322-55.

28. Schreurs PJG, van de Willige G, Tellegen B, Brosschot JF. De Utrechtse Coping Lijst: UCL-handleiding (The Utrecht Coping List). Lisse (Netherlands): Swets\&Zeitlinger; 1988.

29. Van der Grinten MP. Development of a practical method for measuring body part discomfort. In: Kumar S, editor. Advances in industrial ergonomics and safety 4. London: Taylor \& Francis; 1992. p 311-8.

30. Pearcy M. Measurement of back and spinal mobility. Clin Biomech. 1986;1:44-51.

31. Van den Heuvel SG, Boshuizen HC, Hildebrandt VH, Blatter BM, Ariëns GA, Bongers PM. Effect of sporting activity on absenteeism in a working population. Br J Sports Med [serial on the internet]. 2005 Mar [cited 2006 May 30];39(3):[about 15 p.]. Available from: http://bjsm.bmjjournals.com/cgi/reprint/39/3/e15.

32. Jones T, Kumar S. Functional capacity evaluation of manual materials handlers: a review. Disabil Rehabil. 2003;25:17991.

33. Ward MM, Kuzis S. Ceiling effects and the Schober test. J Rheumatol. 2003;30:2732-3.

34. Burdorf A, Rossignol M, Fathallah FA, Snook SH, Herrick RF. Challenges in assessing risk factors in epidemiologic studies on back disorders. Am J Ind Med. 1997;32:142-52.

35. McGill SM. Low back exercises: evidence for improving exercise regimens. Phys Ther. 1998;78:754-65.

Received for publication: 16 June 2005 